\title{
LANCELOT (Lake Nyos carbon emission lowering by olivine treatment)
}

\author{
R. D. Schuiling
}

Received: 27 August 2010/ Accepted: 29 November 2010/Published online: 16 December 2010

(C) The Author(s) 2010. This article is published with open access at Springerlink.com

\begin{abstract}
A catastrophe hit Lake Nyos in Cameroon in August 1986, when a dense cloud of $\mathrm{CO}_{2}$ erupted from the lake and rolled down the slope of the volcano, killing more than 1,700 people. To prevent a repetition, a geyser-like system has been installed, which lifts the bottom waters. When the pressure diminishes, bubbles of $\mathrm{CO}_{2}$ nucleate and bubble upward, thus preventing the accumulation of this greenhouse gas in the bottom waters. In this note, another way of tackling the problem is proposed, by which the $\mathrm{CO}_{2}$ is transformed into bicarbonate in a layer of olivine spread over the lake bottom. Although the volume of the gas is modest at Nyos, the approach can function as a model for other and more voluminous $\mathrm{CO}_{2}$ emissions in the world, to prevent their escape into the atmosphere.
\end{abstract}

Keywords Nyos $\cdot \mathrm{CO} 2$ emission $\cdot$ Olivine $\cdot$ Enhanced weathering

\section{Introduction}

Every year approximately 1-2 billion tons of $\mathrm{CO}_{2}$ are emitted from the Earth and released into the atmosphere. Without a negative feedback system such amounts would quickly lead to extremely high $\mathrm{CO}_{2}$ concentrations in the atmosphere, ending all life, either by asphyxiation or by an extreme greenhouse climate, like on Venus, where such a feedback mechanism is apparently lacking. The Venus atmosphere has a $\mathrm{CO}_{2}$ pressure of 80 bars (250.000 times more than on Earth), leading to surface temperatures of $450^{\circ} \mathrm{C}$ as a consequence of an extreme greenhouse effect. Venus is a dry planet, and liquid water is essential for weathering, which has kept the $\mathrm{CO}_{2}$ pressure in the Earth's atmosphere within reasonable bounds throughout geological history. The $\mathrm{CO}_{2}$ that is released from the Earth, among others by volcanoes, is ultimately stored in carbonate sediments. The total amount of $\mathrm{CO}_{2}$ locked up in limestones and dolomites is at least 1,500 times more (Dunsmore 1992) than the total amount in the biosphere, atmosphere and oceans combined. This means that the biosphere, atmosphere and oceans only act as temporary and rather

R. D. Schuiling $(\bowtie)$

Institute of Geosciences, Utrecht University, Utrecht, Netherlands

e-mail: schuiling@geo.uu.nl 
shortlived intermediate storage for $\mathrm{CO}_{2}$. Before the $\mathrm{CO}_{2}$ became locked up in carbonate sediments, it arrived in the oceans as dissolved bicarbonate in rivers. The negative charge of the bicarbonate ion is balanced by cations released from rocks during weathering. This means that natural weathering, which is the neutralization of an acid (usually carbonic acid) by rocks, is at the base of the mechanism that controls the $\mathrm{CO}_{2}$ concentration of the atmosphere.

Even though storage of carbon as organic carbon is a distant second after storage of carbon as solid carbonates, the release of the stored $\mathrm{CO}_{2}$ in fossil fuels over a short time span is causing a sharp rise of the $\mathrm{CO}_{2}$ levels in the atmosphere. Humanity is burning in a few hundred years the reserves of fossil fuels that have formed over hundreds of millions of years. This is believed by many to trigger a future catastrophic climate change if this rise is permitted to go on. The natural mechanism of chemical weathering is not capable to keep up with this sudden rise. As proposed by Schuiling and Krijgsman (2006) and by Schuiling (2007), the logical way out of this dilemma is to increase the rate of weathering as well to reach a new balance between input and output of $\mathrm{CO}_{2}$ for the Earth's atmosphere. To achieve this, one must select the most reactive rocks, called dunites, containing high concentrations of the mineral olivine (average composition $\left.\left(\mathrm{Mg}_{0.92} \mathrm{Fe}_{0.08}\right)_{2} \mathrm{SiO}_{4}\right)$. Most olivine rocks in the Tropics are covered already by a thick weathering crust consisting mainly of iron (hydr)oxides.

Because of this isolating layer, the underlying olivine rocks contribute little at present to maintain the balance between input and output of $\mathrm{CO}_{2}$. If we remove this weathering crust, mine and mill the underlying olivine-rich rocks, and spread the crushed material over the land surface in a thin layer, we can reactivate their weathering potential. This is the most natural and cheapest way to sustainably counteract extreme climate change (Schuiling and Krijgsman 2006). In order to counteract the greenhouse effect, it makes no difference where we sequester $\mathrm{CO}_{2}$ or what its origin is. It is not necessary to capture it at great expense from the flue gases of coal-fired power plants, if there are cheaper ways to sequester the same amount of $\mathrm{CO}_{2}$ elsewhere in a sustainable way, by stimulating the chemical weathering of suitable silicate rocks.

\section{Application to Lake Nyos}

It will hardly be necessary to remind the reader of the disaster that struck Cameroon on August 27, 1986, when a deadly invisible cloud of $\mathrm{CO}_{2}$ erupted from Lake Nyos and rolled down the slopes of the mountain, killing more than 1,700 people. Since that time, after detailed studies had elucidated the sequence of events that led to this catastrophe, measures have been taken to avoid a repetition, mainly by installing a kind of artificial geyser system by which the $\mathrm{CO}_{2}$ that slowly accumulates near the bottom of the lake is forcibly removed and released in a controlled fashion to the atmosphere (Kling et al. 2005). Carbon dioxide, however, is a greenhouse gas, so if there is a way to sustainably capture this gas instead of releasing it to the atmosphere, this would help to slow down the rise of the $\mathrm{CO}_{2}$ concentration in the atmosphere caused by the burning of fossil fuels.

There is an estimated annual influx of $\mathrm{CO}_{2}$ of $2.6 \times 10^{8}$ mol (Oxner 2005) into the bottom waters of Lake Nyos. Although this is not a huge amount, its accumulation in the lake's bottom waters could potentially lead to a new disaster. To prevent this, a simple and effective technology has been emplaced to remove the $\mathrm{CO}_{2}$ in a controlled manner (Kling et al. 2005). It means, however, that the $\mathrm{CO}_{2}$ is released as a gas into the atmosphere, adding its admittedly small share to the overall climate change problem. Moreover, the 
degassing system will require a continuous energy input, as well as permanent monitoring and maintenance. This makes the system expensive, and the considerable funds required are difficult to obtain (Jones 2010).

It is proposed, therefore, to tackle the problem in a different way via project LANCELOT. If we construct a mound of olivine sand and gravel over the lake bottom where $\mathrm{CO}_{2}$ venting is most active, we may transform the $\mathrm{CO}_{2}$ into the innocuous bicarbonate ion, by the reaction.

$$
\mathrm{Mg}_{2} \mathrm{SiO}_{4}+4 \mathrm{CO}_{2}+4 \mathrm{H}_{2} \mathrm{O} \rightarrow 2 \mathrm{Mg}^{2+}+4 \mathrm{HCO}_{3}^{-}+\mathrm{H}_{4} \mathrm{SiO}_{4}^{0}
$$

This approach can serve a dual purpose, it sequesters $\mathrm{CO}_{2}$ and it curtails, possibly solves the problem of gas venting into Lake Nyos.

The lake has a maximum depth of $206 \mathrm{~m}$ and a volume of $0.15 \mathrm{~km}^{3}$. The sequestration of the annual influx of $\mathrm{CO}_{2}$ would require about 18.000 ton of olivine sand, occupying a volume of around $9.000 \mathrm{~m}^{3}$. As one would like to have an operational system for 10 years at least, it is proposed to deposit a layer of $90.000 \mathrm{~m}^{3}$. When this is done in a layer of $10 \mathrm{~m}$ thick over the deepest part, it has the added advantage that the pressure at which the $\mathrm{CO}_{2}$ bubbles enter the lake water is reduced by one bar.

If the proposed LANCELOT approach works, the $\mathrm{pH}$ of the lake waters should slightly rise and the water will become enriched in magnesium and bicarbonate, and so will the water outflow from the lake. It is reported that the local population uses this water that drains from the lake for consumption. This is certainly not a disadvantage, but will probably be beneficial, as magnesium bicarbonate waters are healthy, and effective against cardiovascular diseases (FAO 2002).

The olivine weathering reaction is exothermic (Schuiling 1964). The thermal effect will be minimal, but thanks to the excellent thermal isolation provided by silicate minerals and depending on the dimensions of the constructed olivine mound and the rate of reaction, the temperature rise may become just large enough to set up a gentle convection system. In such a convection cell, the slightly heated bottom waters flow upward and are replaced by lake water drawn in from the sides of the mound. The mound can be constructed by releasing loads of medium-sized olivine sand over the most active $\mathrm{CO}_{2}$ venting sites, in a layer of several meters thickness. This will help to eliminate the build-up of high $\mathrm{CO}_{2}$ concentrations in the lake's bottom waters. It is not expected that the olivine sand grains will become encrusted by the limited amounts of reaction products, as there is a continual upflow of $\mathrm{CO}_{2}$-rich waters through the pile, carrying the reaction products along. Unreacted $\mathrm{CO}_{2}$ is carried upward with the water plume, and as the pressure drops it will nucleate small bubbles that are released into the atmosphere in a continuous and imperceptible manner.

The LANCELOT test will also serve as a demonstration that the sequestration of naturally emitted $\mathrm{CO}_{2}$ has the same effect on climate as its removal from industrial installations. If successful, it could not only be applied to similar lakes in Africa (Nayar 2009), but also to many geothermal wells with high $\mathrm{CO}_{2}$ discharges, and even to larger areas like near the Greek island of Milos, where annually 2.2 million tons of $\mathrm{CO}_{2}$ bubble out of the seafloor (Dando et al. 1995).

Acknowledgments Richard Cathcart is thanked for critically reading and correcting the paper, and drawing my attention to several related publications. I also wish to thank Dr. G. Pecoraino, who reviewed the paper, and restructured it in a logical manner. 
Open Access This article is distributed under the terms of the Creative Commons Attribution Noncommercial License which permits any noncommercial use, distribution, and reproduction in any medium, provided the original author(s) and source are credited.

\section{References}

Dando PR, Hughes JA, Leahy Y, Niven SJ, Taylor LJ, Smith C (1995) Gas venting rates from submarine hydrothermal areas around the island of Milos, Hellenic Volcanic Arc. Continental Shelf Res 15(8):913-929

Dunsmore HE (1992) A geological perspective on global warming and the possibility of carbon dioxide removal as calcium carbonate mineral. Energy Convers Manag 33:565-572

FAO Document Repository (2002) Human vitamin and mineral requirements. Chapter 14, Magnesium

Jones N (2010) Battle to degas deadly lakes continues. Published online, August 23, Nature 466:1033

Kling GW, Evans WC, Tanykele G, Kusakabe M, Ohba T, Yoshida Y, Hell JV (2005) Degassing Lake Nyos and Monoun: defusing certain disaster. PNAS 102(40):14185-14190

Nayar A (2009) A lakeful of trouble. Nature 460:321-323

Oxner A (2005) Lethal Lakes: the mitigation of dissolved gas hazards in African volcanic lakes. Presentation second annual student world water forum, November 17, 2005

Schuiling RD (1964) Serpentinization as a possible cause of high heat-flow values in and near oceanic ridges. Nature 201(4921):807-808

Schuiling RD ((2007) Let the Earth help us to save the Earth. Unpublished proposal to Virgin Earth Challenge

Schuiling RD, Krijgsman P (2006) Enhanced weathering: an effective and cheap tool to sequester $\mathrm{CO}_{2}$. Clim Change 74(1-3):349-354 